\title{
Risk of narcolepsy in children and young people receiving AS03 adjuvanted pandemic A/H1N1 2009 influenza vaccine: retrospective analysis
}

\author{
Elizabeth Miller consultant epidemiologist ${ }^{1}$, Nick Andrews senior statistician ${ }^{2}$, Lesley Stellitano \\ public health researcher ${ }^{13}$, Julia Stowe research fellow ${ }^{14}$, Anne Marie Winstone public health \\ researcher $^{13}$, John Shneerson consultant physician ${ }^{5}$, Christopher Verity consultant paediatric \\ neurologist $^{13}$
}

${ }^{1}$ Immunisation, Hepatitis and Blood Safety Department, Health Protection Agency, Colindale, London NW9 5EQ, UK ; ${ }^{2}$ Statistics, Modelling, and Economics Department, Health Protection Agency, Colindale, London NW9 5EQ, UK; ${ }^{P}$ IND Research Group, Addenbrooke's Hospital, Cambridge CB2 0QQ, UK; ${ }^{4}$ General and Adolescent Paediatric Unit, Institute of Child Health, University College London, London NW1 2PF, UK; ${ }^{5}$ Respiratory Support and Sleep Centre, Papworth Hospital, Cambridge CB23 3RE, UK

\begin{abstract}
Objective To evaluate the risk of narcolepsy in children and adolescents in England targeted for vaccination with $\mathrm{ASO} 3$ adjuvanted pandemic A/H1N1 2009 vaccine (Pandemrix) from October 2009.

Design Retrospective analysis. Clinical information and results of sleep tests were extracted from hospital notes between August 2011 and February 2012 and reviewed by an expert panel to confirm the diagnosis. Vaccination and clinical histories were obtained from general practitioners.

Setting Sleep centres and paediatric neurology centres in England.

Participants Children and young people aged 4-18 with onset of narcolepsy from January 2008.
\end{abstract}

Main outcome measures The odds of vaccination in those with narcolepsy compared with the age matched English population after adjustment for clinical conditions that were indications for vaccination. The incidence of narcolepsy within six months of vaccination compared with the incidence outside this period measured with the self controlled cases series method.

Results Case notes for 245 children and young people were reviewed; 75 had narcolepsy (56 with cataplexy) and onset after 1 January 2008. Eleven had been vaccinated before onset; seven within six months. In those with a diagnosis by July 2011 the odds ratio was 14.4 (95\% confidence interval 4.3 to 48.5 ) for vaccination at any time before onset and 16.2 (3.1 to 84.5) for vaccination within six months before onset. The relative incidence from the self controlled cases series analysis in those with a diagnosis by July 2011 with onset from October 2008 to December 2010 was 9.9 (2.1 to 47.9). The attributable risk was estimated as between 1 in 57500 and 1 in 52000 doses.
Conclusion The increased risk of narcolepsy after vaccination with ASO3 adjuvanted pandemic A/H1N1 2009 vaccine indicates a causal association, consistent with findings from Finland. Because of variable delay in diagnosis, however, the risk might be overestimated by more rapid referral of vaccinated children.

\section{Introduction}

Narcolepsy is a chronic disorder presenting with excessive daytime sleepiness, often accompanied by a transient loss of muscle tone triggered by strong emotion (cataplexy). Diagnosis is based on clinical criteria and can be confirmed by polysomnography followed by a multiple sleep latency test. ${ }^{1}$ Estimates of prevalence generally range between 25 and 50 per 100000 , though might be less in some populations, possibly because of differences in genetic susceptibility or exposure to aetiological risk factors. ${ }^{2}$ Information on incidence is more limited. Onset can occur at any age $\mathrm{a}^{2}$ but is commonest in those aged 10-19, in whom an incidence of 3.84 per 100000 person years has been reported. ${ }^{3}$ The interval between onset and diagnosis can be long, with a median of 10.5 years in one study. ${ }^{4}$ Diagnostic delay is less in those with cataplexy and in younger patients. ${ }^{5}$ There is a strong association with human leucocyte antigen (HLA) DQB1*0602 and reported associations with environmental factors such as streptococcal infection, ${ }^{6}$ seasonal influenza, ${ }^{7}$ and more recently pandemic A/H1N1 2009 influenza. $^{8}$

In England, a monovalent pandemic strain vaccine containing the oil-in-water adjuvant AS03 (Pandemrix) was introduced in October 2009 during the second wave of infection, initially for people with high risk clinical conditions ${ }^{9}{ }^{10}$ and then in healthy 
children aged under 5 from mid-December 2009. ${ }^{11}$ By March 2010 , around $24 \%$ of healthy children aged $<5$ and $37 \%$ aged 2-15 in a risk group had been vaccinated in England. ${ }^{12} \mathrm{~A}$ second pandemic vaccine was used (Celvepan) but accounted for less than $1 \%$ of the total.

In August 2010 concerns were raised in Finland and Sweden about a possible association between narcolepsy and Pandemrix. ${ }^{13}$ A subsequent cohort study in Finland reported a 13-fold increased risk of narcolepsy after vaccination in children and young people aged 4-19, most of whom had onset within three months after vaccination and almost all within six months. ${ }^{14}$ To evaluate the risk of narcolepsy after vaccination in England we identified cases in those aged under 19 with onset since 1 January 2008 and compared the proportion vaccinated with that in the age matched English population after adjusting for clinical conditions that were indications for pandemic vaccination.

\section{Methods}

\section{Case ascertainment and validation}

Cases in children and young people aged 4-18 at onset of narcolepsy from January 2008 were ascertained from sleep centres and paediatric neurology centres in England. With lists supplied by the British Sleep Society and the British Paediatric Neurology Association we identified 23 centres that saw children. In July 2011 we contacted these 23 centres and 16 replied that they had seen affected children in the relevant time period. To provide an alternative means of case ascertainment we identified all the cases in England recorded in the hospital episode statistics database ${ }^{15}$ with the ICD-10 (international classification of diseases, 10th revision) diagnosis code G47.4 (narcolepsy and cataplexy) in the same age group in the same time period. Clinical information including the presence of cataplexy and results of relevant tests including polysomnography, multiple sleep latency test, HLA type, and hypocretin concentrations were extracted from case notes during visits to the 16 study centres from August 2011 to February 2012. Details of the clinical features and test results of cases will be reported elsewhere. Patients' general practitioners were sent a questionnaire to ascertain history of pandemic and seasonal influenza vaccination, date of onset of symptoms, date of first healthcare consultation for a sleep problem, and any underlying clinical condition for which pandemic vaccine was indicated. Information on infections preceding narcolepsy was also sought. These data were reviewed by three narcolepsy experts (blinded to vaccination status) who confirmed the cases in which the diagnosis was definite- that is, narcolepsy with cataplexy or narcolepsy without cataplexy according to international classification of sleep disorders criteria. ${ }^{1}$ Cases not meeting these criteria but with a convincing clinical history were classified as probable narcolepsy. The remainder were excluded because of insufficient information and were not included in the analysis.

\section{Index dates-definitions}

The date of symptom onset was the earliest date of excessive daytime sleepiness or cataplexy as given by the general practitioner or recorded in the centre notes. When the exact date was not available we used the mid-point of the month.

The date of first known healthcare contact was the earliest recorded consultation for a sleep related problem as reported by the general practitioner or in the centre notes.
The key centre visit was when all cases known at the centre were systematically ascertained; cases identified on an ad hoc basis after this were not included.

The date of diagnosis was the earliest date that identified an affected patient at the key centre visit, either on the basis of a clinical history and sleep study confirming narcolepsy or because there was sufficient clinical information to diagnose probable narcolepsy.

\section{Statistical analysis}

We assessed the association between vaccination and narcolepsy using the case coverage method ${ }^{16}$ : for each patient with narcolepsy in the study the population coverage was ascertained for children of the same age (in months on 30 September 2009) at the relevant index date (that is, date of symptom onset) and with the same risk group status (in a group or not). The association was calculated as the odds ratio for vaccination in the cases compared with the matched population. This was done with logistic regression with the outcome as vaccinated (yes/no) in the cases and with an offset for the log odds of the matched coverage. As the outcome is rare, odds ratios approximate to relative risks. Vaccine coverage by age in years and risk group status came from weekly electronic reports to the Birmingham research unit of the Royal College of General Practitioners by a representative sample of 98 general practices in England for the period September 2009 to August $2010 .{ }^{17} \mathrm{We}$ analysed patient level electronic records extracted from the practices to derive coverage data for specific age and risk groups. To obtain coverage within 12 weeks or six months before an index date we matched the coverage at the index date and at the date 12 weeks or six months earlier and calculated the difference in coverage. Cases categorised by the experts as definite and probable narcolepsy were combined for all analyses. The primary analysis used first symptoms as the index date and was restricted to diagnoses by 31 July 2011 . We carried out sensitivity analyses including all patients with a diagnosis by the key centre visit, using first healthcare contact or diagnosis as the index date, not matching on risk group status, or increasing population coverage by a relative $20 \%$ (for example, $10 \%$ increasing to $12 \%$ ). Analyses were performed based on vaccination within 12 weeks, within six months, and at any time before the index date.

We carried out a separate analysis using the self controlled case series method ${ }^{18}$ to estimate the incidence of symptom onset within three and six months after vaccination relative to the incidence outside this period (the baseline). Because pandemic influenza vaccination started in October 2009 the observation period for each individual started on 1 October 2009 and ended on 31 December 2010. In a second analysis we used a start date of October 2008 to allow inclusion of additional unexposed person time in the baseline. Analyses were performed with all those with a diagnosis by the key visit date and also restricted to those with a diagnosis by July 2011. Adjustment for time period was made with calendar month of onset. Adjustment by age was not necessary as this was relatively stable within the study period.

\section{Results}

\section{Vaccine coverage}

We extracted information on 160400 individuals aged 2-18 from the Royal College of General Practitioners database. Of these, $14400(9.0 \%)$ were in a clinical risk group, mainly because of asthma. Table $1 \Downarrow$ gives the uptake of pandemic vaccine by August 2010 by age and risk group status and the 
estimated number of first doses given in England by this date, based on 2009 population estimates. ${ }^{19}$ The cumulative vaccine uptake by day, age, and risk status is consistent with the initial targeted vaccination of risk groups followed by all children aged under 5 (fig $1 \Downarrow$ ).

\section{Study cases}

\section{Review of clinical records}

We reviewed the clinical records in 245 cases identified by clinicians and/or from the hospital episode statistics database search at the 16 study centres. Although in all cases the diagnoses or hospital admission dates were after January 2008, we excluded 130 because onset of symptoms was before January 2008 and 23 because the diagnosis had not been confirmed by the sleep centre. This left 92 cases for independent review by the narcolepsy expert panel: in 10 there was insufficient information to assign a diagnosis, in three the date of diagnosis was after the key visit, three patients were outside the 4-18 age range, and in one the onset was before January 2008. Of the 75 remaining cases, 66 were definite according to the international classification of sleep disorders criteria (56 had narcolepsy with cataplexy and 10 had narcolepsy without cataplexy). The nine remaining were considered probable narcolepsy. Table 2 shows the demographic and clinical features in these 75 cases $\Downarrow$; in 55 cases the patients has received a diagnosis by July 2011 .

\section{Cases identified from hospital episode statistics}

Of the 162 cases identified via this database in England, 130 were identified from the 16 study centres. Only 35 fitted our case definition and were included in the analysis. In the 95 excluded cases, 62 patients had onset before January 2008, and in 25 the diagnosis in the hospital episode statistics database was not confirmed by the study centre (case notes in eight such cases were not available for review). The remaining 32 cases identified from hospital episode statistics were in centres that had not reported cases or were cases at non-centre hospitals; these 32 cases were distributed as follows: two hospitals had four cases each, two had three cases each, and 18 had single cases.

\section{Vaccination history}

We obtained vaccination history and risk group status in all 75 study cases; none of the patients with a diagnosis of probable narcolepsy was vaccinated (table 2). Of the 11 definite cases in which the patient had previously received pandemic vaccine, six had onset within three months, one within three to six months, and four between seven and 14 months after vaccination; all had received Pandemrix and age at vaccination ranged between 3 and 16 . Figure $2 \Downarrow$ shows the 75 cases by month of symptom onset and whether they had previously receieved vaccine, together with vaccine uptake. The vaccinated patient with onset in 2011 received Pandemrix in 2011, when residual stocks were used instead of seasonal vaccine. ${ }^{20}$ Two were reported to have an influenza-like illness in the six months before first symptoms, neither of whom was vaccinated.

\section{Case coverage analysis}

Table 3 shows the results of the case coverage analysis $\Downarrow$ for patients who had received a diagnosis by July 2011 and by the key study visit with and without adjustment for risk group status. Odds ratios were significantly increased in all analyses; odds ratios without matching on risk group status were generally higher as were those based on date of onset of symptoms. The odds ratio with symptom onset as the index date and with the assumption that all vaccinated patients were in a risk group was 5.0 (1.3 to 19.3$)$ for vaccination within six months and $3.3(1.2$ to 8.7) for "vaccinated at any time," while increasing coverage by a relative $20 \%$ gave a risk group adjusted odds ratio of 13.0 (2.5 to 68.3) for vaccination within six months and 11.5 (3.4 to 39.2) for "vaccinated at any time."

\section{Self controlled case series analysis}

Only 18 cases diagnosed by the key visit had onset of symptoms between October 2009 and December 2010, of whom seven were unvaccinated, one was vaccinated after onset, and 10 were vaccinated before onset (five within 84 days, six within 182 days, four more than 182 days before). Restriction of cases to those diagnosed by July 2011 excluded four unvaccinated cases and one case vaccinated more than 182 days before onset. Starting the observation period from October 2008 added another 22 unvaccinated cases and two more cases vaccinated after onset. Relative incidence estimates were only significantly raised when we included the period from October 2008 in the baseline (table $4 \Downarrow$ ).

\section{Attributable risk}

For calculation of the vaccine attributable risk we used the odds ratio of 14.4 based on symptom onset as the index date, diagnosed by July 2011, and "vaccinated at any time" (table 3). If the odds ratio is used to approximate relative risk (RR), the attributable fraction ((RR-1)/RR)) is 13.4/14.4, which applied to the 10 vaccinated patients in this analysis gives an estimate of 9.3 attributable cases. To estimate the number of doses given to the population the cases came from, we used the number of doses given in England to those aged 3-18 by September 2009 (668 000 from table 1, as the youngest vaccinated patient was aged 3 at vaccination). We then adjusted this number assuming a range of $80 \%$ to $100 \%$ for the proportion of cases captured, which gives a range of 534400 to 668000 doses. The figure of $80 \%$ used as a minimum proportion of cases captured was obtained by comparing the number of hospital episode statistics cases coded as G47.4 for the period 1 January 2008 to 20 November 2010 that were from the 16 centres ( 130 cases) to the total number of G47.4 cases in the hospital episode statistics database in England for this period (162). The estimated attributable risk is therefore between 9.3/534 400 and 9.3/668 000 (1 per 57500 to 1 per 52000 doses).

\section{Discussion \\ Principal findings}

This study shows a significantly increased risk of narcolepsy in children who received the AS03 adjuvanted pandemic strain vaccine in England. Our case coverage method gave an odds ratio of 14.4 (4.3 to 48.5 ) for the primary analysis and is consistent with the relative risk of 13 reported from Finland in a retrospective cohort study. ${ }^{14}$ The lack of reported cases in other European states and Canada after the initial case reports from Finland and Sweden in August $2010^{13}$ led to speculation that some unidentified factor was operating in these countries and that the association, if real, might be restricted to these Scandinavian populations. ${ }^{21}$ Our study confirms the signal raised from Finland and Sweden ${ }^{13}$ and indicates that the association is not restricted to those populations.

The increased risk found in our study and in Finland could be because the vaccine accelerates onset of narcolepsy, which would lead to a consequent deficit in incident cases in subsequent years with no vaccine attributable risk in the longer 
term. Evaluation of this would require late follow-up. The effect would be difficult to detect in England given the low vaccine coverage but might be detected in Finland and Ireland, ${ }^{22}$ where coverage was substantially higher. A spuriously high risk would also be generated if the clinical features of the vaccine associated cases prompted earlier referral, as suggested by the abrupt onset and unusual severity reported in one small case series. ${ }^{23}$ A later follow-up could ascertain relatively more unvaccinated than vaccinated patients with onset in 2010-11 with a consequent reduction in the relative risk. The attributable risk, however, could increase as a result of ascertainment of additional vaccinated patients. Our attributable risk estimate of between one in 57500 and 52000 doses was lower than reported from Finland (one in 16000 ), despite a similar odds ratio/relative risk and annual incidence before vaccine, which was 0.42 per 100000 in our study (based on the 29 incident cases in 2008) and 0.31 in Finland between 2002 and 2009. ${ }^{24}$ This could be because of differences in population susceptibility or because proportionately more vaccine in Finland was given to adolescents, in whom incidence is highest. The same attributable fraction applied to a higher absolute incidence generates a higher attributable risk.

\section{Strengths and weaknesses of our study}

Our aim was to conduct a national study in England, and we therefore contacted all sleep centres that see affected children and in addition approached paediatric neurologists to whom such children might have been initially referred. Based on replies to our initial contact in July 2011, we focused on the 16 sleep/neurology centres in England that reported that they had seen affected children with onset since 2008 . We did not visit the seven remaining centres that made a negative return, though it is possible that relevant cases were not identified at the time or were referred to them after July 2011. Cases in the hospital episode statistics database that were not in the 16

sleep/neurology centres together accounted for 20\% (32/162) of the G47.4 hospital episode statistics diagnoses in England in the study period. Most of these cases would not have been eligible for inclusion judging by the hospital episode statistics cases reviewed at the 16 study centres (where only 35/120 (29\%) with available information were eligible). The G47.4 diagnosis code, however, had low sensitivity (as admission is not a necessary part of case management), and it is possible that eligible cases in England were missed. Under the worst case scenario- that, based on the hospital episode statistics diagnoses, only $80 \%$ of eligible cases were captured and that those not captured were all in unvaccinated patients - this would add another four unvaccinated cases to the number with onset after October 2009 diagnosed by July 2011 (increasing the total from 17 to 21 in table 3 among those eligible for vaccination at any time before onset). Adding in four cases (one in a risk group) still results in an increased odds ratio of 9.2 (3.1 to 27.2). Although the case coverage analysis gave a significantly raised odds ratio, the number of cases in patients with onset in 2010 $(n=16)$ was lower than in $2009(n=21)$. This deficit was particularly evident for unvaccinated patients; there were six in 2010 compared with 21 in 2009. While delays to diagnosis might partially explain this, based on the distribution of intervals from onset to diagnosis in previous years we might reasonably have expected about seven more unvaccinated children in 2010 to have received a diagnosis by July 2011 . The "missing" cases in unvaccinated patients could be just random variation, but to assess the impact of the dearth of unvaccinated patients in 2010 we added seven cases in 2010 with onset dates across the year, one of which was in a patient in a risk group for vaccination.
This had the effect of decreasing the odds ratio for vaccination within six months from 16.2 to 8.3 (95\% confidence interval 2.2 to 31.5$)$.

The results of our self controlled case series analysis were less clear. This method requires a prespecified risk period after vaccination in which the incidence relative to the baseline incidence is compared. ${ }^{25}$ Based on the onsets in the Finnish case $^{14}$ we defined the risk period as within six months. This resulted in the inclusion in the baseline of four patients with symptoms more than six months after vaccination. When more unexposed time was included in the baseline by starting person time from October 2008 the self controlled case series analysis gave results closer to the case coverage estimates. The finding that four of the 11 cases associated with vaccines in our study were in children with onset longer than six months after vaccination could reflect lack of precision in ascertaining onset date or the fact that in our study were included patients with diagnosis in 2011 whereas in the Finnish study follow-up ended in December 2010. Our longer follow-up period would have allowed patients with a later onset to receive a diagnosis. Another assumption of the self controlled case series method that used person time before vaccination is that the narcolepsy condition should not influence whether or not an individual subsequently gets vaccinated. This seems unlikely but could occur if narcolepsy is regarded by some general practitioners as an indication for influenza vaccination or if the symptoms lead to individuals being more or less likely to visit their general practitioner and be offered vaccination opportunistically.

Apart from the inherent problems in conducting timely studies of the association between narcolepsy and exposure to a vaccine first used in late 2009, our study has other potential limitations. There can be difficulty in accurately defining onset of symptoms, which could result in recall bias. Onset dates, however, were obtained from medical records made before the putative association had generated public interest, and the date of first healthcare contact should be objective. Random inaccuracies in defining onset would reduce the estimate of relative risk rather than generating a falsely high estimate. Our case coverage approach depended on the accuracy and representativeness of the Royal College of General Practitioners' coverage data. The patient level data used for the analysis were extracted by established procedures used for estimates of effectiveness of annual influenza vaccine. ${ }^{26}$ The Royal College of General Practitioners' population is closely matched to the national population in terms of age, sex, deprivation index, and prescribing patterns, ${ }^{27}$ and our coverage estimates by age and risk group status were similar to those in a national coverage survey that provided aggregate data by broad age groups. ${ }^{12}$ The case coverage method also depends on the absence of a confounding variable for which coverage could not be stratified. Apart from age and time period, which were adjusted for in the analysis, we are not aware of any other variable that could generate the size of effect observed. Although there is no reported association between having a co-morbidity for which influenza vaccination is recommended and likelihood of subsequently developing narcolepsy, we adjusted for this variable because of its high correlation with vaccination and hence potential to be a confounder. The reduction in odds ratio seen after this adjustment might reflect a true association or be caused by chance. If the association is real then failure to identify whether a vaccinated patient was in a risk group for vaccination could result in spuriously high odds ratios. Under the extreme assumption that all patients were in a risk group, however, there was still an increased odds ratio of 5.0 (1.3 to 19.3) for vaccination within six months before onset. Finally, 
our attempt to investigate an association with pandemic influenza was based on a history of influenza-like illness. As a clinical history is not specific, and some infections are asymptomatic, we cannot exclude H1N1 infection as an aetiological factor in some cases. It seems unlikely, however, that previous infection would be more likely in vaccinated patients.

\section{Strengths and weaknesses in relation to other studies}

It is difficult to rapidly test the putative association between vaccination and narcolepsy because of the long and variable interval between onset and diagnosis ${ }^{4}$ and the considerable potential for underdiagnosis. ${ }^{28}{ }^{29}$ Pandemic vaccine was first used in October 2009 and many patients with onset in 2010 and 2011 will not be yet have a diagnosis. The potential for an accelerated diagnosis in patients in whom an association with vaccination is suspected vaccine once the signal was raised is considerable. We sought to limit this bias by restricting our primary analysis to patients with a diagnosis by July 2011, when reports from Finland and Sweden had not generated media or public interest in the United Kingdom, the first spike in internet searches for "narcolepsy" being in December 2011.

Others have sought to limit ascertainment bias by restricting cases to those with onset or first healthcare contact before media attention. ${ }^{14}{ }^{30}$ As diagnosis is a necessary condition for case capture, however, ascertainment might still be biased because of preferential inclusion of vaccinated patients with accelerated diagnosis after the generation of public interest. Censoring cases by date of diagnosis and using this as the index date for analysing previous vaccine exposure blurs any temporal relation between vaccination and onset because of variable diagnostic delays, and patients vaccinated after onset but before diagnosis will be categorised as "exposed." In our study, as in Finland, risk estimates were substantially lower when we used diagnosis as the index date. An unpublished case-control study that pooled data from five European countries that used the AS03 adjuvanted or other H1N1 pandemic strain vaccine failed to find an association when the multiple sleep latency test date was used as the index date (odds ratio $1.6,95 \%$ confidence interval 0.5 to 6.1), but when they additionally restricted cases to those with symptom onset between April 2009 and June 2010 the odds ratio increased to 4.6 (1.7 to 13.7$).{ }^{31}$ As this additional analysis was one of several sensitivity analyses conducted, however, its relevance was perhaps overlooked, resulting in the conclusion that the signal from Finland and Sweden could not be confirmed. ${ }^{31}$ In our study, to minimise ascertainment bias and improve precision in defining the risk period after vaccination, we censored case inclusion by date of diagnosis and used symptom onset as the index date for the primary analysis.

Other epidemiological approaches to assessing the association have been adopted. A study in one Swedish county linking a pandemic vaccination register with a healthcare database, while underpowered to investigate the risk of narcolepsy, reassuringly found little evidence of an association with other neurological or autoimmune disorders. ${ }^{32}$ Ecological studies that evaluate changes in population incidence of narcolepsy associated with the use of pandemic vaccine have also been reported. ${ }^{243}$ Establishing causality through such an approach, however, is problematic as other factors can affect the incidence of patients with the diagnosis. Also, unless vaccine coverage is high, as in Finland ${ }^{24}$ an increase might be difficult to detect at the population level. A recent study derived a pooled incidence estimate from automated healthcare databases in six European countries to monitor changes associated with the use of pandemic vaccines. ${ }^{33}$ Estimates of baseline incidence, however, varied widely between countries, probably reflecting differences in case capture between databases, and significant increases and decreases in incidence in individual countries unrelated to vaccine use were observed.

\section{Policy implications and future research}

In conclusion, we found evidence of an increased risk of narcolepsy in children who received pandemic A/H1N1 2009 influenza vaccine (Pandemrix) in England. Despite attempts to minimise ascertainment bias, the potential for overestimation of risk remains because of more rapid referral of vaccinated patients. Long term follow-up of the cohorts exposed to the vaccine is needed to properly evaluate the attributable risk.

As a precaution, based on the preliminary reports from Sweden and Finland and pending the outcome of confirmatory studies, in July 2011 the European Medicines Agency changed the indication for use of Pandemrix vaccine in people aged under 20 to those for whom seasonal trivalent vaccine was not available and for whom prevention of A/H1N1 2009 influenza was considered necessary. ${ }^{34}$ Its licence, however, remains valid, and the vaccine can still be manufactured and sold in any European Union country. While further use of the ASO3 adjuvanted vaccine for prevention of seasonal A/H1N1 2009 seems unlikely, our findings have implications for the future licensure and use of AS03 adjuvanted pandemic vaccines containing different subtypes such $\mathrm{H} 5$ or $\mathrm{H} 9$. Further studies to assess the risk, if any, associated with the other A/H1N1 2009 vaccines used in the pandemic, including those with and without adjuvants, are also needed to inform the use of such vaccines in the event of a future pandemic.

We thank Douglas Fleming, Royal College of General Practitioners, for supplying the RCGP data extracts for the vaccine coverage estimates and Stephen Evans, London School of Hygiene and Tropical Medicine, for review of the statistical analysis plan. The authors gratefully acknowledge the participation of Paul Gringras, Evelina Children's Hospital, St Thomas' Hospital, London, and Zenobia Zaiwalla, Sleep Disorders Service, John Radcliffe Hospital, Oxford, in the expert panel. We thank the members of the British Sleep Society and the British Paediatric Neurology association, and the general practitioners who assisted with the follow-up. The HES data are re-used with permission of the Health and Social Care Information Centre.

Contributors: All the authors were involved in study design. JS, CV, AMW, and LS extracted clinical information from the centre notes. JS extracted the HES cases and conducted the GP follow-up. JSh assisted in recruitment of sleep centres and was a member of the expert panel. NA conducted the statistical analysis, and EM wrote the first draft of the paper. All authors contributed to the final version and had access to the dataset.

Funding: The study was funded by the Department of Health policy research programme and the Health Protection Agency. The views expressed in the publication are those of the authors and not necessarily those of the Department of Health, England. The funding source had no role in data collection, data analysis, data interpretation, or writing of the report. CV, JS, AMW, and LS were supported by a grant from the Department of Health research and development directorate (No 039/0031).

Competing interests: All authors have completed the ICMJE uniform disclosure form at www.icmje.org/coi_disclosure.pdf (available on request from the corresponding author) and declare: no support from any organisation for the submitted work; no financial relationships with any organisations that might have an interest in the submitted work in 


\section{What is already known on this topic}

A potential association between ASO3 adjuvanted A/H1N1 2009 pandemic vaccine (Pandemrix) and narcolepsy was first identified in Scandinavian countries after clinicians in sleep centres reported temporal associations

An epidemiological study from Finland reported a 13-fold increased risk in children and young people aged 4-19

There is a need for a robust study to independently test the association in a non-Scandinavian country where no signal has been raised by clinician reports

\section{What this study adds}

The increased risk of onset of narcolepsy in children and young people after the AS03 adjuvanted pandemic vaccine is not confined to Scandinavian populations

The magnitude of the increased risk found in English children and young people is similar to that reported from Finland

the previous three years; no other relationships or activities that could appear to have influenced the submitted work.

Ethical approval: HPA has approval for England from the National Information Governance Board for Health and Social Care (NIGB) (PIAG ref: PIAG 03-(c)/2001), which allows us access to patient identifiable information for purposes of monitoring vaccine safety.

Data sharing: No additional data available.

1 American Academy of Sleep Medicine. International classification of sleep disorders, 2nd ed. Diagnostic and coding manual. American Academy of Sleep Medicine, 2005.

2 Longstreth WT Jr, Koepsell TD, Ton TG, Hendrickson AF, van Belle G. The epidemiology of narcolepsy. Sleep 2007;30:13-26.

3 Silber MH, Krahn LE, Olson EJ, Pankratz VS. The epidemiology of narcolepsy in Olmsted County, Minnesota: a population-based study. Sleep 2002;25:197-202.

4 Morrish E, King MA, Smith IE, Shneerson JM. Factors associated with a delay in the diagnosis of narcolepsy. Sleep Med 2004;5:37-41.

5 Furuta H, Thorpy MJ, Temple HM. Comparison in symptoms between aged and younger patients with narcolepsy. Psychiatry Clin Neurosci 2001;55:241-2.

6 Aran A, Lin L, Nevsimalova S, Plazzi G, Hong SC, Weiner K, et al. Elevated anti-streptococcal antibodies in patients with recent narcolepsy onset. Sleep 20091;32:979-83.

7 Picchioni D, Hope CR, Harsh JR. A case-control study of the environmental risk factors for narcolepsy. Neuroepidemiology 2007;29:185-92.

8 Han F, Lin L, Warby SC, Faraco J, Li J, Dong SX, et al. Narcolepsy onset is seasonal and increased following the $2009 \mathrm{H} 1 \mathrm{~N} 1$ pandemic in China. Ann Neurol 2011;70:410-7.

9 Department of Health. Salisbury D, Ramsay M, Noakes K, eds. Immunisation against infectious disease. Stationery Office, 2006:193-94. www.dh.gov.uk/en/ Publicationsandstatistics/Publications/PublicationsPolicyAndGuidance/DH_079917.

10 Chief Medical Officer's Update. The H1N1 swine flu vaccination programme. Department of Health, 2009. www.dh.gov.uk/en/Publicationsandstatistics/Lettersandcirculars/ Dearcolleagueletters/DH 107169.

11 Chief Medical Officer's Update. CMO letter announcing amendment of Pandemrix $\AA_{\text {license }}$ to allow a one-dose schedule in children. Department of Health, 2009. www.nelm.nhs.uk en/NeLM-Area/News/2009---December/16/CMO-letter-announcing-amendment-ofPandemrix-license-to-allow-a-one-dose-schedule-in-children-/

12 Pandemic $\mathrm{H} 1 \mathrm{~N} 1$ (swine) influenza vaccine uptake amongst patient groups in primary care in England 2009/10, DH/HPA, DH/HPA28, Oct 2010 www.dh.gov.uk/prod_consum_dh/ groups/dh_digitalassets/@dh/@en/@ps/documents/digitalasset/dh 121014.pdf.

13 National Institute for Health and Welfare recommends discontinuation of Pandemrix vaccinations. National Institute for Health and Welfare, 2010. www.thl.fi/en_US/web/en/ pressrelease?id=22930

14 Nohynek H, Jokinen J, Partinen M, Vaarala O, Kirjavainen T, Sundman J, et al. AS03 adjuvanted $\mathrm{AH} 1 \mathrm{~N} 1$ vaccine associated with an abrupt increase in the incidence of childhood narcolepsy in Finland. PLoS One 2012;7:e33536.

15 Hospital Episode Statistics. www.hesonline.nhs.uk/Ease/servlet/ContentServer? sitelD=1937.

16 Farrington CP. Control without separate controls: evaluation of vaccine safety using case-only methods. Vaccine 2004;22:2064-70.

17 Royal College of General Practitioners Research and Surveillance Centre. Annual report 2009. www.rcgp.org.uk/clinical and research/rsc/annual reports.aspx.

18 Farrington CP, Nash J, Miller E. Case series analysis of adverse reactions to vaccines: a comparative evaluation. Am J Epidemiol 1996;143:1165-73.
19 Population Estimates Unit. Estimated resident population mid-2009 by single year. Office of National Statistics, 2009. www.ons.gov.uk/ons/rel/pop-estimate/population-estimatesfor-uk--england-and-wales--scotland-and-northern-ireland/2009/index.html.

20 Influenza Immunisation Uptake Monitoring Programme, England. IMM form. www.dh.gov. uk/prod consum dh/groups/dh digitalassets/documents/digitalasset/dh_129856.pdf.

21 Global Advisory Committee on Vaccine Safety. Statement on narcolepsy and vaccination. World Health Organization, 2011 www.who.int/vaccine_safety/topics/influenza/pandemic/ h1n1_safety_assessing/narcolepsy_statement/en/index.html.

22 National Narcolepsy Study Steering Committee. Investigation of an increase in the incidence of narcolepsy in children and adolescents in 2009 and 2010. http://healthupdate gov.ie/wp-content/uploads/2012/04/Final_Report_of_National_Narcolepsy_Study_Steering_ Committee-latest1.pdf.

23 Dauvilliers Y, Montplaisir J, Cochen V, Desautels A, Einen M, Lin L, et al. Post-H1N1 narcolepsy-cataplexy. Sleep 2010;33:1428-30.

24 Partinen M, Saarenpää-Heikkilä O, Ilveskoski I, Hublin C, Linna M, Olsén P, et al. Increased incidence and clinical picture of childhood narcolepsy following the $2009 \mathrm{H} 1 \mathrm{~N} 1$ pandemic vaccination campaign in Finland PLoS One 2012;7:e33723.

25 Andrews N. Epidemiological designs for vaccine safety assessment: methods and pitfalls. Biologicals 2012:40:389-92.

26 Hardelid P, Fleming DM, Andrews N, Barley M, Durnall H, Mangtani P, et al. Effectiveness of trivalent and pandemic influenza vaccines in England and Wales 2008-2010: results from a cohort study in general practice. Vaccine 2012;30:1371-8.

27 Fleming DM, Miles J. The representativeness of sentinel practice networks. J Public Health (Oxf) 2010;32:90-6.

28 Allsopp MR, Zaiwalla Z. Narcolepsy. Arch Dis Child 1992;67:302-6.

29 Doherty L, Crowe C, Sweeney B. National narcolepsy survey. Ir Med J 2010;103:110, 112-3.

30 Medical Products Agency. Occurrence of narcolepsy with cataplexy among children and adolescents in relation to the $\mathrm{H} 1 \mathrm{~N} 1$ pandemic and Pandemrix vaccinations. Results of a case inventory study by the MPA in Sweden 2009-2010. www.lakemedelsverket.se/upload/ nyheter/2011/Fallinventeringsrapport pandermrix 110630.pdf.

31 ECDC Technical Report Narcolepsy in association with pandemic influenza vaccination A multi-country European epidemiological investigation. http://vaesco.net/vaesco/results/ main/04/text_files/file/ECDC\%202012\%20VAESCO\%20Narco\%20report\%20FULL.pdf.

32 Bardage C, Persson I, Ortqvist A, Bergman U, Ludvigsson JF, Granath F. Neurological and autoimmune disorders after vaccination against pandemic influenza $A(H 1 N 1)$ with a monovalent adjuvanted vaccine: population based cohort study in Stockholm. Sweden BMJ 2011;343:d5956.

33 Wijnans L, Lecomte C, de Vries C, Weibel D, Sammon C, Hviid A, et al. The incidence of narcolepsy in Europe: before, during, and after the influenza A(H1N1)pdm09 pandemic and vaccination campaigns. Vaccine 2012;31:1246-54.

34 European Medicines Agency. Pandemrix assessment report. 21st July 2011. www.ema. europa.eu/docs/en GB/document library/EPAR - Assessment Report - Variation/ human/000832/WC500118056. pdf.

\section{Accepted: 30 January 2013}

\section{Cite this as: BMJ 2013;346:f794}

This is an open-access article distributed under the terms of the Creative Commons Attribution Non-commercial License, which permits use, distribution, and reproduction in any medium, provided the original work is properly cited, the use is non commercial and is otherwise in compliance with the license. See: http://creativecommons.org/licenses/by$\mathrm{nc} / 2.0 /$ and http://creativecommons.org/licenses/by-nc/2.0/legalcode. 


\section{Tables}

Table 1/ Coverage of vaccination with ASO3 adjuvanted pandemic A/H1N1 2009 vaccine by August 2010* in England by age and risk group, and total doses based on RCGP age specific coverage estimates

\begin{tabular}{|c|c|c|c|c|c|}
\hline $\begin{array}{l}\text { Age in years } \\
\text { (September 2009) }\end{array}$ & $\%$ Coverage overall & $\begin{array}{c}\% \text { Coverage in risk } \\
\text { groups }\end{array}$ & $\begin{array}{c}\% \text { Coverage in non-risk } \\
\text { groups }\end{array}$ & Population of England & $\begin{array}{l}\text { Estimated No of people } \\
\text { vaccinated } \\
\text { in England }\end{array}$ \\
\hline 2 & 31.9 & 46.0 & 31.2 & 639700 & 204086 \\
\hline 3 & 29.2 & 46.1 & 28.2 & 619800 & 181119 \\
\hline 4 & 20.5 & 40.6 & 18.9 & 605800 & 124324 \\
\hline 5 & 4.7 & 34.0 & 2.1 & 597800 & 28277 \\
\hline 6 & 4.1 & 30.6 & 1.7 & 576700 & 23771 \\
\hline 7 & 4.4 & 30.7 & 1.5 & 559400 & 24393 \\
\hline 8 & 4.4 & 30.3 & 1.7 & 557800 & 24277 \\
\hline 9 & 4.4 & 30.2 & 1.7 & 571500 & 24948 \\
\hline 10 & 4.6 & 31.0 & 1.9 & 586600 & 26999 \\
\hline 11 & 4.6 & 28.5 & 1.9 & 596800 & 27747 \\
\hline 12 & 4.7 & 29.4 & 2.0 & 612300 & 28958 \\
\hline 13 & 4.9 & 29.1 & 2.1 & 608700 & 29623 \\
\hline 14 & 4.3 & 24.6 & 1.9 & 612100 & 26476 \\
\hline 15 & 4.5 & 25.6 & 2.2 & 628700 & 28472 \\
\hline 16 & 4.0 & 22.6 & 1.9 & 640900 & 25336 \\
\hline 17 & 3.6 & 20.8 & 1.8 & 666900 & 24093 \\
\hline 18 & 2.9 & 15.5 & 1.7 & 686400 & 19634 \\
\hline Total aged 2-4 & 27.3 & 43.9 & 26.2 & 1865300 & 509529 \\
\hline Total aged 5-18 & 4.3 & 27.1 & 1.9 & 8502600 & 363004 \\
\hline
\end{tabular}

*About 200000 doses of pandemic vaccine were given in winter of $2010-11^{21}$ but no age or risk group specific coverage data were available. 
Table 2/ Demographic and clinical features of 75 patients with narcolepsy in cases included in analysis according to ASO3 adjuvanted pandemic A/H1N1 2009 vaccination

Category

Never vaccinated Vaccinated after first symptoms Vaccinated before first symptoms Total

Age at diagnosis (years):

\begin{tabular}{|c|c|c|c|c|}
\hline $4-8$ & 18 & 3 & 7 & 28 \\
\hline $9-13$ & 21 & 1 & 2 & 24 \\
\hline $14-18$ & 21 & 0 & 2 & 23 \\
\hline \multicolumn{5}{|l|}{ Sex: } \\
\hline Male & 33 & 2 & 8 & 43 \\
\hline Female & 27 & 2 & 3 & 32 \\
\hline \multicolumn{5}{|l|}{ Diagnostic category: } \\
\hline Narcolepsy and cataplexy & 42 & 4 & 10 & 56 \\
\hline Narcolepsy, no cataplexy & 9 & 0 & 1 & 10 \\
\hline Probable narcolepsy & 9 & 0 & 0 & 9 \\
\hline \multicolumn{5}{|c|}{ Risk group for influenza vaccine: } \\
\hline No & 49 & 2 & 5 & 56 \\
\hline Yes & 11 & 2 & 6 & 19 \\
\hline \multicolumn{5}{|c|}{ 2010-11 seasonal vaccine given: } \\
\hline No & 56 & 3 & 9 & 68 \\
\hline Yes (before symptoms) & 1 & 0 & 0 & 1 \\
\hline Yes (after symptoms) & 3 & 1 & 2 & 6 \\
\hline
\end{tabular}


Table 3| Case coverage analysis in patients with narcolepsy showing odds ratios for receipt of ASO3 adjuvanted pandemic A/H1N1 2009 vaccine before narcolepsy using different index dates, follow-up periods, and risk intervals

\begin{tabular}{|c|c|c|c|c|c|c|}
\hline \multirow[b]{2}{*}{$\begin{array}{l}\text { Interval before } \\
\text { index date }\end{array}$} & \multirow[b]{2}{*}{$\begin{array}{c}\text { No of } \\
\text { patients } \\
\text { vaccinated }\end{array}$} & \multirow{2}{*}{$\begin{array}{c}{ }^{*} \text { Total No of } \\
\text { patients eligible } \\
\text { for vaccination } \\
\text { in interval } \\
\text { before index } \\
\text { date }\end{array}$} & \multicolumn{2}{|c|}{ Not matching on risk group } & \multicolumn{2}{|c|}{ Matching on risk group } \\
\hline & & & Average coverage & Odds ratio $(95 \% \mathrm{Cl})$ & Average coverage & Odds ratio $(95 \% \mathrm{Cl})$ \\
\hline \multicolumn{7}{|c|}{ Index date: symptom onset } \\
\hline \multicolumn{7}{|c|}{ Censored July $312011 \uparrow:$} \\
\hline 12 weeks & 5 & 10 & 0.060 & $34.7(7.4$ to 163.7$)$ & 0.098 & $18.4(3.7$ to 91.6$)$ \\
\hline 6 months & 6 & 10 & 0.072 & 33.1 (8.1 to 135.7$)$ & 0.151 & 16.2 (3.1 to 84.5$)$ \\
\hline Any time & 10 & 17 & 0.089 & $22.2(7.9$ to 62.1$)$ & 0.160 & $14.4(4.3$ to 48.5$)$ \\
\hline \multicolumn{7}{|c|}{ Censored at key visitt: } \\
\hline 12 weeks & 5 & 12 & 0.051 & $30.8(7.1$ to 134.2$)$ & 0.082 & 17.8 (3.7 to 86.3$)$ \\
\hline 6 months & 6 & 13 & 0.060 & $23.2(6.5$ to 82.0$)$ & 0.119 & $12.5(2.9$ to 53.1$)$ \\
\hline Any time & 11 & 26 & 0.083 & $11.0(4.8$ to 25.4$)$ & 0.132 & 8.3 (3.1 to 22.3$)$ \\
\hline \multicolumn{7}{|c|}{ Index date: first healthcare contact } \\
\hline \multicolumn{7}{|c|}{ Censored July $312011 \dagger:$} \\
\hline 6 months & 7 & 24 & 0.049 & 12.7 (4.6 to 34.8$)$ & 0.094 & $6.7(2.1$ to 21.0$)$ \\
\hline Any time & 10 & 32 & 0.067 & $8.4(3.7$ to 19.1$)$ & 0.124 & $4.7(1.9$ to 11.8$)$ \\
\hline \multicolumn{7}{|c|}{ Censored at key visitt: } \\
\hline 6 months & 7 & 26 & 0.045 & $12.5(4.5$ to 34.1$)$ & 0.087 & 6.7 (2.1 to 20.8$)$ \\
\hline Any time & 11 & 42 & 0.067 & $6.3(3.0$ to 13.4$)$ & 0.112 & 4.0 (1.7 to 9.3$)$ \\
\hline \multicolumn{7}{|c|}{ Index date: diagnosis } \\
\hline \multicolumn{7}{|c|}{ Censored July 312011 t: } \\
\hline Any time & 12 & 44 & 0.072 & $5.9(2.9$ to 12.0$)$ & 0.129 & 3.3 (1.5 to 7.4$)$ \\
\hline \multicolumn{7}{|c|}{ Censored at key visit $†$ : } \\
\hline Any time & 14 & 55 & 0.071 & 5.4 (2.8 to 10.2$)$ & 0.122 & 3.2 (1.6 to 6.8 ) \\
\hline
\end{tabular}

*As almost all pandemic vaccine was given by end of April 2010 cases were excluded from within 12 weeks and within 6 month analysis if index date was after August 2010 and November 2010, respectively, leading to exclusion of one case vaccinated in 2011.

†Censoring date for inclusion by diagnosis. 
Table 4| Relative incidence estimates and $95 \%$ confidence intervals for onset of narcolepsy in different periods after vaccination with ASO3 adjuvanted pandemic A/H1N1 2009 vaccine using self controlled case series analysis

\begin{tabular}{|c|c|c|c|}
\hline Analysis & $\begin{array}{l}\text { Period of risk after vaccination } \\
\text { (days) }\end{array}$ & Cases $^{*}$ & $\begin{array}{c}\text { Relative incidence }(95 \% \mathrm{Cl}) \text { adjusted for } \\
\text { period }\end{array}$ \\
\hline Symptoms Oct 2009 to Dec 2010 & $0-84$ & 5 & $2.9(0.6$ to 12.9$)$ \\
\hline Diagnosed by key visit & $0-182$ & 6 & $1.4(0.3$ to 6.4$)$ \\
\hline Symptoms Oct 2009 to Dec 2010 & $0-84$ & 5 & $2.3(0.5$ to 11.0$)$ \\
\hline Diagnosed by July 2011 & $0-182$ & 6 & $1.4(0.2$ to 7.5$)$ \\
\hline Symptoms Oct 2008 to Dec 2010 & $0-84$ & 5 & 7.1 (1.7 to 29.3$)$ \\
\hline Diagnosed by key visit & $0-182$ & 6 & $5.2(1.3$ to 20.2$)$ \\
\hline Symptoms Oct 2008 to Dec 2010 & $0-84$ & 5 & 10.1 (2.2 to 46.3$)$ \\
\hline Diagnosed by July 2011 & $0-182$ & 6 & 9.9 (2.1 to 47.9$)$ \\
\hline
\end{tabular}

${ }^{\star}$ Excludes one vaccinated case with onset within three months who received pandemic vaccine after December 2010 when residual stocks were used in place of seasonal influenza vaccine. 


\section{Figures}
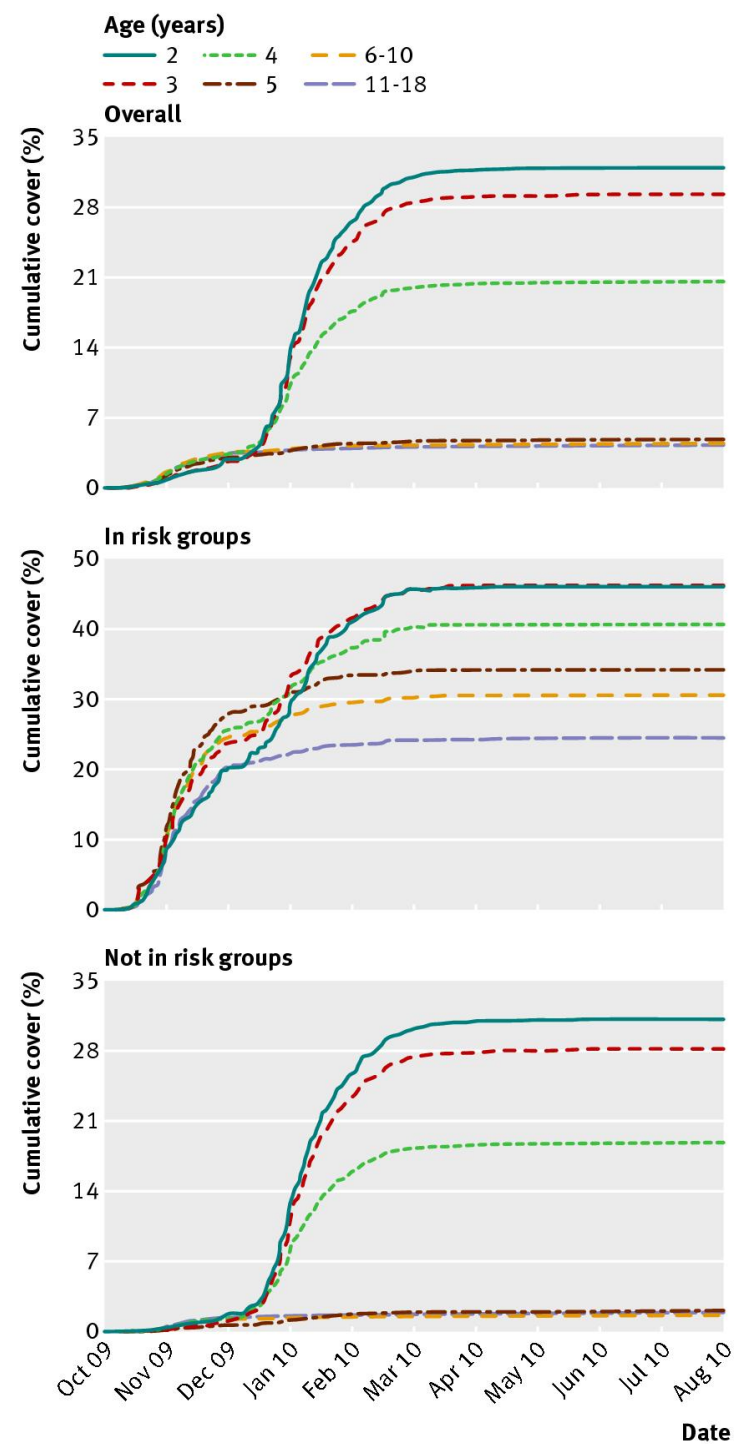

Fig 1 Cumulative population uptake by day of pandemic A/H1N1 2009 influenza vaccine by age at September 2009 and risk group status

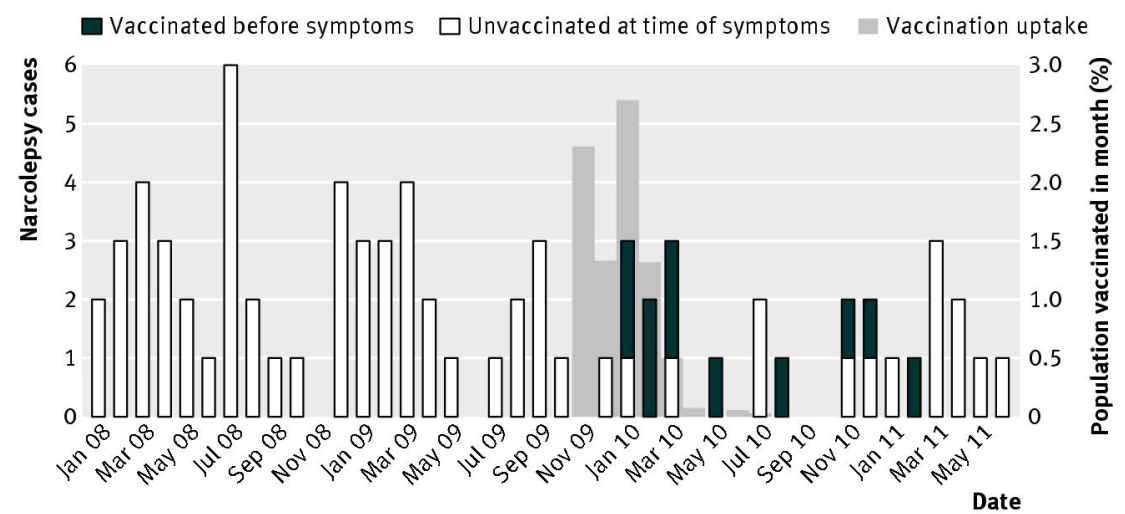

Fig 2 Number of cases of narcolepsy by month and year of onset according to vaccination status at onset. Also shown is population vaccine coverage with pandemic vaccine 